\title{
Protective cellular immunity generated by cross-presenting recombinant overlapping peptide proteins
}

\author{
Lili Cai ${ }^{1, *}$, Jianbo Zhang ${ }^{2, *}$, Renying Zhu ${ }^{1}$, Weixing Shi ${ }^{1}$, Xiaobing Xia ${ }^{1}$, Mark \\ Edwards ${ }^{3}$, William Finch ${ }^{3}$, Anthony Coombs ${ }^{3}$, Ju Gao ${ }^{2}$, Kangwen Chen ${ }^{2}$, Sophie \\ Owen $^{5}$, Shisong Jiang ${ }^{1,3,4,5}$ and Wenshu Lu ${ }^{1,4}$ \\ 1Oxford Vacmedix (Changzhou) Company Ltd, Changzhou, Jiangsu, China \\ ${ }^{2}$ The No.2 People's Hospital of Dali, Dali, Yunnan, China \\ ${ }^{3}$ Oxford Vacmedix UK Limited, Oxford, United Kingdom \\ ${ }^{4}$ Shanghai JW Inflinhix Co Ltd, Shanghai, China \\ ${ }^{5}$ Department of Oncology, University of Oxford, Oxford, United Kingdom \\ *These authors contributed equally to this work \\ Correspondence to: Wenshu Lu, email: luws@vacmedix.cn \\ Shisong Jiang, email: shisong.jiang@oncology.ox.ac.uk
}

Keywords: vaccines, peptide immunization, overlapping peptide, antigen processing, cross-presentation

Received: June 14, 2017 Accepted: August 14, $2017 \quad$ Published: August 24, 2017

Copyright: Cai et al. This is an open-access article distributed under the terms of the Creative Commons Attribution License 3.0 (CC BY 3.0), which permits unrestricted use, distribution, and reproduction in any medium, provided the original author and source are credited.

\section{ABSTRACT}

Priming of naive $\mathrm{CDB}^{+}$and $\mathrm{CD4}^{+} \mathrm{T}$ cells by dendritic cells (DCs) requires effective antigen presentation on both MHC class I and II molecules. We have developed a novel technology to use recombinant overlapping peptides (ROP) that stimulate both $\mathrm{CD8}^{+}$and $\mathrm{CD4}^{+} \mathrm{T}$ cell immune responses. The single chain protein of a ROP is made up of overlapping peptides linked by the target sequence (LRMK) for cathepsin S, a protease found in the endosomes of DCs. We designed synthetic genes encoding ROPs derived from ovalbumin (OVA), tuberculosis protein (CFP10-ESAT6), human papilloma virus (HPV) protein (E7) and survivin, a protein commonly over-expressed in tumour cells. An epitope from ROP-OVA was cross-presented and detected by a $\mathrm{CDB}^{+} \mathrm{T}$ cell receptor-like antibody (TCR like Ab). Human DCs pulsed with ROP-survivin activated CD8 $^{+} T$ cells. CD4-low PBMCs from HIV and TB co-infected patients recognized ROPCFP10-ESAT6 compared to a soluble form of the antigen. Immunization of mice with ROP-survivin or ROP-HPV-E7 generated specific cellular immune responses and protected mice from inoculation with melanoma B16 cells expressing survivin or HPV-E7 proteins. Together these data provide evidence to support ROP as a central component of a new platform for therapeutic vaccines and diagnostics.

\section{INTRODUCTION}

Priming naive antigen-specific $\mathrm{CD} 8^{+}$and $\mathrm{CD} 4^{+} \mathrm{T}$ cells requires effective antigen presentation by MHC class I and II molecules on the surface of antigen presenting cells (APC), such as dendritic cells (DC) $[1,2]$. For CD8 ${ }^{+}$ $\mathrm{T}$ cells, an antigen must be endogenous, i.e. expressed in or delivered to the cytoplasmic compartment of an APC, before being processed to produce peptide epitopes that are bound to MHC class I in the endoplasmic reticulum (ER) [3]. In contrast, exogenous antigens are endocytosed by APCs into endosomes before merging with lysosomes. Here the antigens are degraded and processed, resulting in peptide epitopes bound to MHC class II. The MHC-peptide complex then moves to the surface of the APC where it can stimulate $\mathrm{CD}^{+} \mathrm{T}$ cells [4]. In some situations, crosspresentation, a process in which exogenous antigen is presented by MHC class I on APCs to activate $\mathrm{CD} 8^{+} \mathrm{T}$ cells occurs. The mechanisms by which this cross-presentation occurs remain unclear $[5,6]$.

Cross-presentation is important for the priming of $\mathrm{CD}^{+} \mathrm{T}$ cells; however, the efficiency of this route of antigen presentation is low [6-8]. As a result, current strategies for stimulating $\mathrm{CD} 8^{+} \mathrm{T}$ cell immunity are focused on in situ expression of antigens, achieved by delivering DNA encoding the target protein into the 
cytoplasm of APCs. This is the basis of DNA vaccines or immunization using bacterial or viral vectors encoding target antigens as vaccines. These vaccines have been in development for a number of years, but so far most of them remain in experimental stages. One limitation they share is that they are associated with unwanted immune responses to vector elements that can suppress immunity to the target antigen [9].

Along with others, we have demonstrated that an exogenously applied pool of overlapping peptides is able to stimulate both $\mathrm{CD} 4^{+}$and $\mathrm{CD} 8^{+} \mathrm{T}$ cell immunity to a level that has clinical significance [10-12]. Moreover, we have demonstrated that a pool of overlapping peptides is more effective than the native protein in antigen presentation $[13,14]$. Furthermore, the use of overlapping peptides more comprehensively represents the range of potential $\mathrm{T}$ cell epitopes. With a view to reducing the cost of manufacture and overcoming the regulation difficulties of multiple synthetic peptides, we made an artificial protein composed of overlapping peptides taken from the target protein, interspersed by a protease cleavage sequence. We describe such artificial antigens as recombinant overlapping peptide proteins (ROPs). The ROP version of an antigen can be cleaved into overlapping peptides in vitro by incubation with the relevant protease [14]. This ROP approach greatly reduces the cost of producing a pool of peptides and has shown efficacy in stimulating both $\mathrm{CD} 8^{+}$and $\mathrm{CD}^{+}$immune responses and protection from viral infection in animals [14].

However, there are several caveats that may impede the development of this technology, mainly from the manufacturing and regulation point of view. First, it is difficult to quality-control the manufacture of the peptide mixtures and achieve batch to batch consistency. Secondly, similar to using overlapping synthetic peptides as vaccines, a pool of the peptides may be regarded as multiple entities when applying for an approval from a regulatory body. Thirdly, the involvement of protease in vitro to digest the ROP vaccines and the extra procedures to separate the enzyme from the mixture of peptides afterward may result in additional regulatory hurdles and costs. These drawbacks reduce the potential benefits of using ROPs in vaccine development.

Protein-based subunit vaccines are exogenous antigens and as such are not efficient in stimulating $\mathrm{CD} 8^{+} \mathrm{T}$ cell immunity. Nonetheless, vaccines of this type are widely used and have many advantages over other forms of vaccine for the purposes of manufacture, regulatory approval and vaccine administration. This led us to consider the use of intact ROPs for immunization. It occurred to us that a ROP protein could be cleaved into the desired set of overlapping peptides within the endosomal compartment, if the peptides are joined by a linker sequence recognized by an APC protease. We hypothesized that if the peptides had access the cytoplasmic compartment, they might be transported to the lumen of the ER where they would bind MHC class
I molecules with subsequent presentation on the cell surface.

In this study, we adapt the synthetic gene approach previously used in ROP production to test this endogenous cleavage and cross-presentation. We explore the ability of exogenously administered artificial protein to undergo digestion within the APC and to stimulate both $\mathrm{CD} 8^{+}$ and $\mathrm{CD} 4^{+} \mathrm{T}$ cells. We use ovalbumin as a model antigen to determine the ability of exogenous ROP-ovalbumin (ROP-OVA) to lead to cross-presentation of the major $\mathrm{T}$ cell epitope (SIINFEKL). We then explore the wider applicability of the approach by examining $\mathrm{T}$ cell responses induced by ROPs based on three clinically significant antigens: human papillomavirus E7, the tuberculosis protein CFP10-ESAT6 and survivin, an antigen up-regulated in a large number of tumour types.

\section{RESULTS}

\section{Recombinant protein antigens containing overlapping sequences}

Cathepsin $\mathrm{S}$ is an enzyme situated in the endosomes of an APC [14, 15]. Its main physiological function is to cleave the chaperone protein from MHC class II [15]. We therefore selected the minimal cathepsin $\mathrm{S}$ cleavage site (LMRK) to link the overlapping peptides in the artificial ROP vaccines [16]. To test our hypothesis, we made 4 recombinant overlapping peptides: ROP-OVA (based on ovalbumin), ROP-HPV (based on HPV E7), ROP-TB (based on CFP10 and ESAT6) and ROP-survivin.

\section{ROP-OVA can be cross-presented via the MHC class I pathway}

In order to assess the presentation of ROPs by MHC class I on APCs in vitro, we first tested the ROP-OVA construct. We examined antigen processing and presentation of ROP-OVA in DC2.4 cells (H-2b) with native ovalbumin protein (OVA) as the comparator (Figure 1A). Antigen presentation was assessed using a TCR-like antibody that specifically recognizes the ovalbumin peptide SIINFEKL when bound to the mouse MHC class I molecule $\mathrm{H}-2^{\mathrm{b}}$ on the surface of APCs. No H2b-SIINFEKL complex was detected when DC2.4 cells were incubated with native OVA (Figure 1B, red peak in the left panel). However, the H-2 ${ }^{\mathrm{b}}$ SIINFEKL complex was readily detected after incubation of ROP-OVA with DC2.4 cells for 13 hours (Figure 1B, red peak in the right panel), indicating that ROP-OVA was efficiently cross-presented on MHC class I.

\section{Activation of $\mathrm{CD8}^{+} \mathrm{T}$ cells by ROP-pulsed DCs}

In order to assess the uptake of ROP antigens by human DCs, we incubated NHS (N-Hydroxy Succinimide) ester-labelled ROP-HPV with human PBMCs for 36 hours in the presence of IL-4 and GM-CSF, followed by staining 
for CD54. Expression of CD54 was used as a marker for an enriched population of monocyte derived DCs. Analysis by flow cytometry indicated that the majority of ROP-HPV was taken up by CD54 ${ }^{+}$cells (Figure 2A).

A

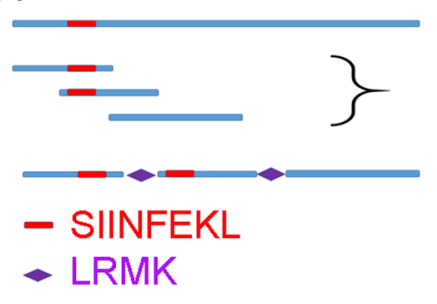

We then assessed whether ROP pulsed DCs could activate $\mathrm{CD} 8^{+} \mathrm{T}$ cells. $\mathrm{CD} 8^{+} \mathrm{T}$ cells, $\mathrm{DCs}$ and $\mathrm{CD} 19^{+} \mathrm{B}$ cells were isolated from human PBMCs. The DCs were stimulated with native survivin or ROP-survivin proteins
OVA

Overlapping peptides

\section{OVA ROP}
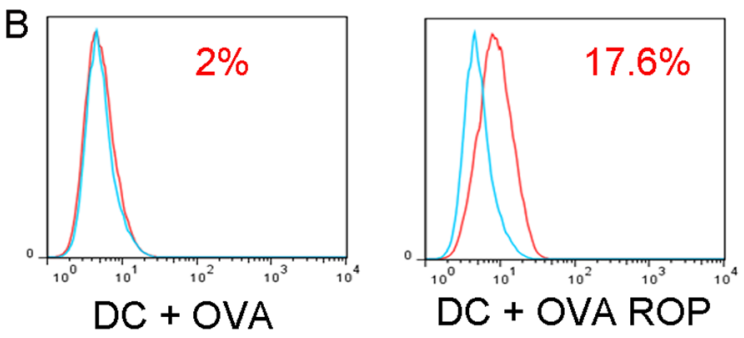

(Blue peak $=\mathrm{DC}+\mathrm{PBS}$ )

Figure 1: Presentation of ROP-OVA on MHC class 1 molecules. (A) Recombinant overlapping peptides derived from native OVA were linked by LRMK, the target sequence of cathepsin S. SIINFEKL is the epitope presented on mouse H-2b. (B) Comparison of SIINFEKL presentation on dendritic cells after incubation of DC2.4 cells with $50 \mu \mathrm{g} / \mathrm{ml}$ native OVA or ROP-OVA for 13 hours. The experiment was repeated twice.

A

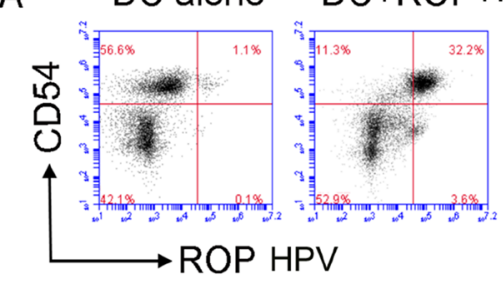

$\mathrm{C}$

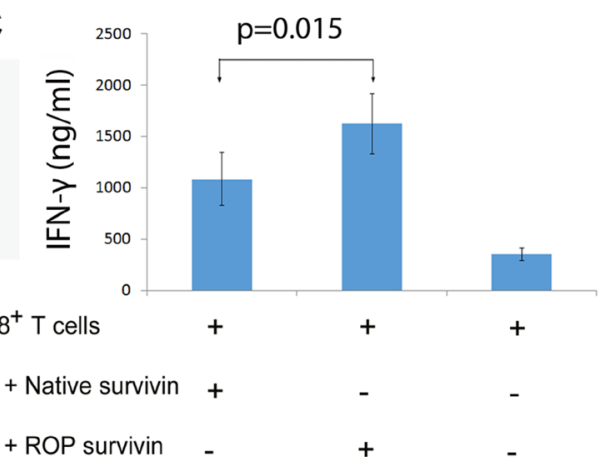

B

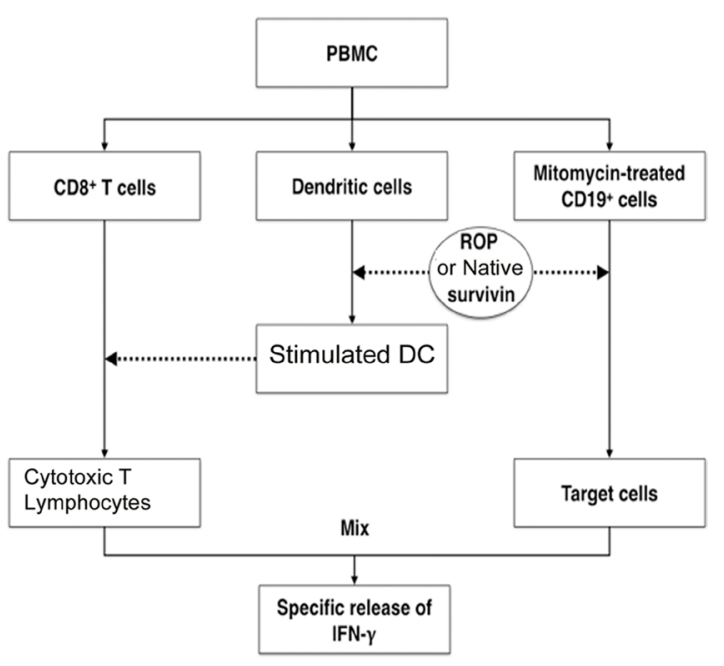

Figure 2: Presentation of ROP on DCs activates $\mathbf{C D 8}^{+} \mathbf{T}$ cells. (A) ROP is taken up by CD54 cells. PBMCs were incubated with $50 \mu \mathrm{g} / \mathrm{ml} \mathrm{N}$-HydroxySuccinimide-labelled ROP-HPV for 36 hours in the presence of $50 \mathrm{IU} / \mathrm{ml}$ IL-4 and $1000 \mathrm{IU} / \mathrm{ml}$ GM-CSF. The experiment was repeated twice. (B) Protocol to test for $\mathrm{CD} 8^{+}$killing of target cells. DCs were isolated from PBMCs and stimulated with ROP-survivin for 3 days. DCs were then cultured with naive $\mathrm{CD}^{+} \mathrm{T}$ cells for 7 days. Specific $\mathrm{CD} 8^{+} \mathrm{T}$ cells were measured for IFN- $\gamma$ production upon culture with ROP-survivin pulsed, mitomycin treated CD19+ target cells. (C) IFN- $\gamma$ production by cytotoxic T lymphocytes following incubation with ROP- survivin stimulated DCs upon culture with target cells. Naive CD8 ${ }^{+} \mathrm{T}$ cells following incubation with the ROP or native survivin stimulated DCs became cytotoxic T lymphocytes. ROP survivin primed CD8 ${ }^{+} \mathrm{T}$ cells were more cytotoxic than native Survivin primed $\mathrm{CD} 8^{+} \mathrm{T}$ cells. $\mathrm{CD} 8^{+} \mathrm{T}$ cells alone were not cytotoxic $\mathrm{T}$ lymphocytes, and secreted very little IFN- $\gamma$ when incubated with target cells. 
for 3 days. $\mathrm{CD}^{+} \mathrm{T}$ cells were then co-cultured with the primed DCs cells for 7 days prior to testing them for specific killing of ROP-survivin or survivin protein pulsed target cells (mitomycin-treated autologous CD19+ B cells) in vitro (Figure $2 \mathrm{~B}$ ). Functionally, DC-ROP-survivin stimulated $\mathrm{CD}^{+} \mathrm{T}$ cells showed an increase in INF- $\gamma$ secretion when incubated with ROP-bearing CD $19^{+} \mathrm{B}$ cells. This increased INF- $\gamma$ secretion was greater for target cells primed with ROP-survivin than those primed with native survivin protein (Figure $2 \mathrm{C}, P=0.015$ ).

\section{ROP-TB-ESAT6-CFP10 is recognized by CD4 ${ }^{+}$ depleted $\mathrm{T}$ cell populations from HIV-TB co-infected patients}

To investigate whether ROP could be recognized by $\mathrm{CD}^{+} \mathrm{T}$ cells, we tested PBMCs from human immunodeficiency virus (HIV) and tuberculosis (TB) co-infected patients who had a depleted $\mathrm{CD}^{+} \mathrm{T}$ cell population but a normal $\mathrm{CD}^{+} \mathrm{T}$ cell population. We compared ROP with a current commercially available TB diagnostic kit (T-SPOT.TB). The kit uses two sets of overlapping synthetic peptides, T-spot 1 (overlapping peptides of ESAT6) and T-spot 2 (overlapping peptides of
CFP10), to stimulate TB reactive T cells in PBMCs taken from a patient. In general, however, peptide synthesis gives lower yields and is much less cost effective than recombinant manufacture [17].

Firstly, we incubated PBMC samples from eight clinically diagnosed TB patients with two ELISpot-based diagnostic kits. The commercially available T-SPOT.TB contains synthetically generated overlapping peptides from ESAT-6 (T-spot1) and CFP10 (T-spot2). In the second kit, the overlapping synthetic primers were replaced with an ROP based on two linked TB antigens (ESAT-6 and CFP10). Diagnosis of TB was found to be directly comparable between ROP-ESAT6-CFP10 and the established T-SPOT.TB assay in six out of the eight patients. In the remaining two samples, the kit based on ROP-ESAT-6-CFP 10 was more sensitive than the T-SPOT.TB assay (patients 1 and 6 - Figure 3A).

Next, to test the efficiency of ROP antigen presentation to $\mathrm{CD}^{+} \mathrm{T}$ cells, we used PBMCs from HIV and TB co-infected patients with depleted CD4 ${ }^{+}$ lymphocyte levels and examined their ability to respond to TB antigens. PBMCs from patients were incubated with either ROP-ESAT6-CFP10, or a soluble wild-type form of the linked native antigen (ESAT6-CFP10). As
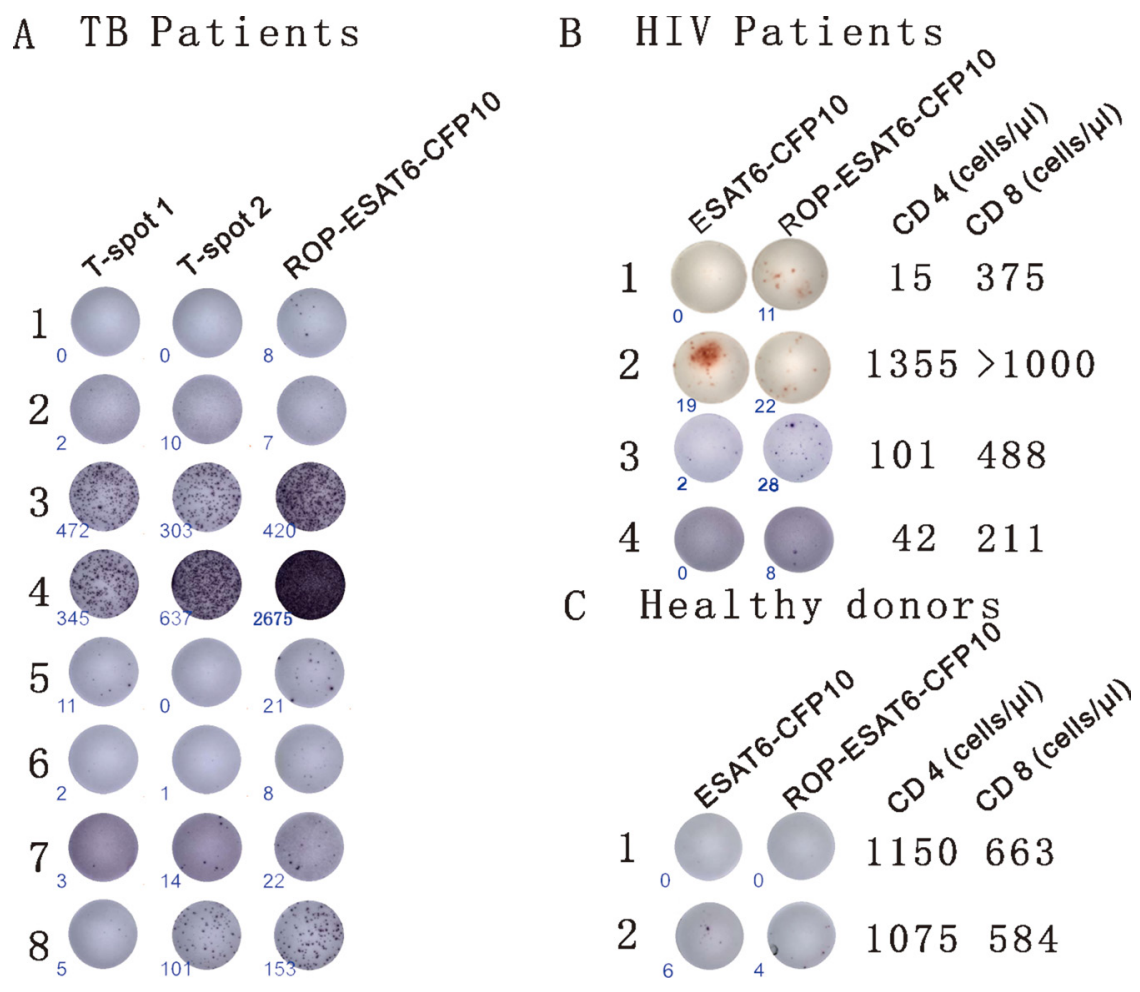

Figure 3: ROPs for the diagnosis of TB. (A) Detection of TB with ROP antigens is comparable to current diagnostic tests. PBMCs from 8 TB patients (clinically diagnosed as TB infection) were incubated with the T-SPOT.TB1 (synthetic overlapping peptides of ESAT6) and T-SPOT. TB2 (synthetic overlapping peptides of CFP10) or ROP-ESAT6-CFP10 ELISpot-based tests for 13 hrs. An individual cell producing IFN- $\gamma$ is represented by appearance of a spot with number of spots at lower left corner. (B) ROP antigen detects TB infection in HIV- related CD4 ${ }^{+}$depleted PBMCs. PBMCs from 4 HIV/TB co-infected individuals were incubated with $50 \mu \mathrm{g} / \mathrm{ml}$ wildtype ESAT6CFP10 or ROP-ESAT6-CFP10 for 18 hours (the third patient was from a different experiment). An individual cell producing IFN- $\gamma$ is represented by appearance of a spot with number of spots at lower left corner. CD4 and CD8 counts are listed on the right of the cell picture. (C) ROP antigen does not stimulate $\mathrm{T}$ cell reaction in healthy donors. 
shown in Figure $3 \mathrm{~B}$, IFN- $\gamma$ production in response to the native antigen was dependent on the presence of $\mathrm{CD}^{+}$ lymphocytes (Patient 2), suggesting epitopes could only be presented via MHC class II. In contrast, the ROP version of the same antigen was equally effective at inducing IFN- $\gamma$ responses in $\mathrm{CD}^{+}$high (patient 2 ) and $\mathrm{CD}^{+}$depleted individuals (Patients 1, 3 and 4), suggesting that epitopes were presented efficiently to $\mathrm{CD}^{+} \mathrm{T}$ cells (Figure 3B). PBMCs isolated from healthy donors have no response or very low response to ESAT6-CFP10 or ROPESAT6-CFP10 stimulation (Figure 3C).

\section{ROP immunization protects mice from challenge with tumour cells expressing the cognate antigen}

Human papilloma virus (HPV) and survivin are both associated with tumours. We next investigated the effect of ROP-HPV or ROP-survivin immunization on tumour models in vivo. Mice (14 per group) were immunized three times with either ROP-HPV-E7, native HPV-E7 or adjuvant alone with a three-week interval between immunizations. Three weeks after the last immunization, four mice from each group were sacrificed to assess antigen-specific responses. The remaining mice were challenged with B16 cells expressing HPV-E7 and survival rates were followed for 25 days after HPV expressed-B16 cells injection (Figure 4A). Immunization with both HPV-E7 protein and ROP-HPV-E7 resulted in PBMCs that were strongly reactive to re-challenge with the corresponding antigen (Figure $4 \mathrm{~B}$ - only data for ROP-HPV-E7 shown); and significantly extended survival times. Furthermore, ROP-HPV-E7 was at least as effective as immunization with native HPV, with a strong trend towards enhanced survival (Figure 4C).

A similar picture emerged when the experiment was repeated using ROP-survivin as the antigen (Figure 5A). Mice immunized with ROP-survivin or a vaccine based on native survivin protein both showed significant antigen specific responses, and these correlated with increased survival after challenge with B16 cells expressing survivin, though survival was significantly better in mice immunized with ROP-survivin (Figure 5B and 5C).

\section{DISCUSSION}

Overlapping peptides have a compelling set of properties that make them very attractive candidates for vaccines designed to elicit $\mathrm{T}$ cell responses. They lack the

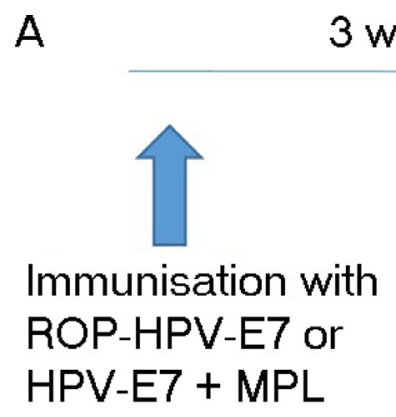

\section{wks}

3 wks

3 wks

B
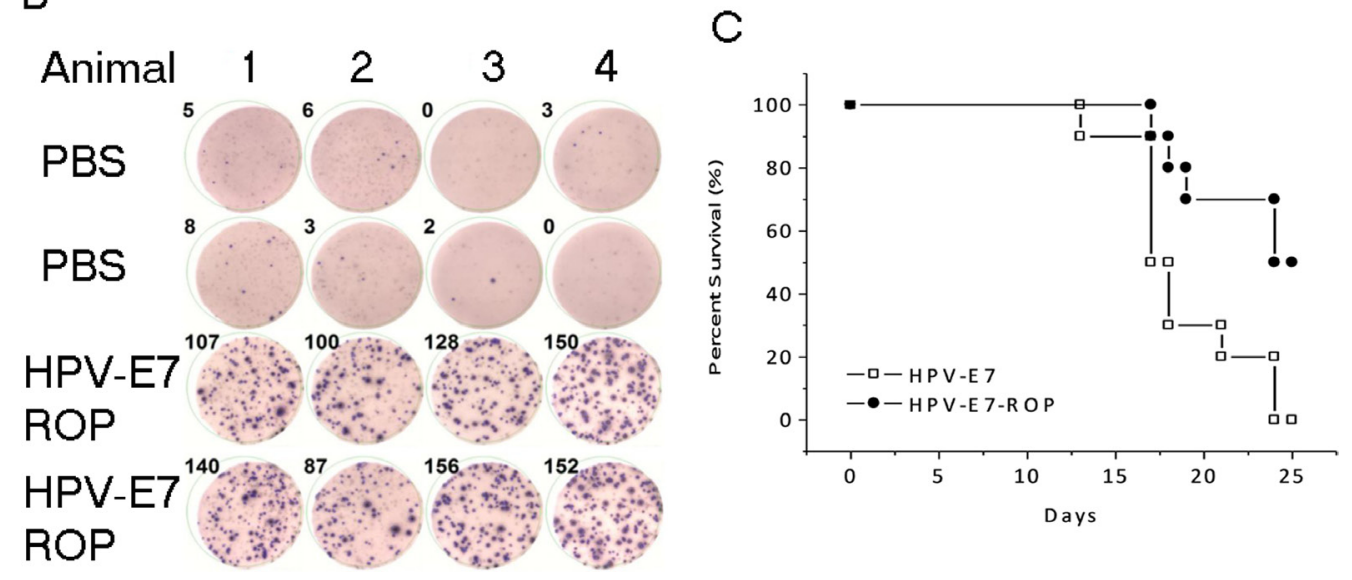

Figure 4: Immunization with ROP-HPV increases survival times in a mouse tumour model. (A) Experimental timeline. Mice were immunized with ROP-HPV-E7 $(n=14)$ or native HPV-E7 $(n=14)$ at day 0 and then further immunized twice at 3 week intervals with antigen ${ }^{+}$monophosphoryl lipid A (MPL). Four mice from each group were sacrificed for ELISpot analysis and the remaining mice were subjected to challenge with B16 cells expressing HPV-E7 3 weeks later. (B) IFN- $\gamma$ release from activated lymphocytes. Following immunization PBMCs were incubated with an ELISpot test using ROP-HPV-E7 (data for native antigen primed mice not shown). (C) Survival rates for mice immunized with ROP-HPV-E7 compared to protein HPV-E7 following challenge with B16 cells expressing HPV-E7. 
viral or bacterial elements present in vector-based vaccines that can dominate the desired response or lead to damaging off target responses. Unlike single peptide epitope vaccines, they offer the potential for much broader responses, avoiding the need for HLA typing of individuals. They can also benefit from the improved persistence of response resulting from the use of longer peptides.

The use of ROPs as a more practical and economic way of generating sets of overlapping peptides brings their clinical application a significant step nearer. In this study, we have shown that in vivo processing of ROPs can occur if the peptides are connected by a suitable cleavage site. This suggests that initial loading with ROP leads to endosomal uptake into DCs, where the ROP is processed into overlapping peptides by cathepsin $\mathrm{S}$. The peptides are then cross-presented on MHC class I molecules. This process has general applicability, as we have demonstrated that it occurs with ROPs based on four different antigens (ovalbumin, TB-CFP10-ESAT6, HPV-E7 and survivin).
Furthermore, the in vivo processed peptides are cross-presented efficiently, as measured by $\mathrm{T}$ cell effector function. This can occur even in CD4 lymphocyte depleted individuals. Finally, this functional in vitro presentation translates into effective in vivo immunity as shown by the ability to enhance survival when immunized mice are challenged with tumour cells carrying the cognate antigen.

Immunization with tumour specific antigens is an effective way of stimulating immune responses against tumours, but the magnitude and duration of the response is not usually sufficient on its own to result in tumour clearance. This has led to the conclusion that effective cancer immunotherapy will need to combine approaches that enhance immune responses - such as non-specific checkpoint inhibition and immune stimulation, with an antigen specific component involving immunization with tumour antigens $[18,19]$. This study demonstrates that antigens based on recombinant overlapping peptides have significant potential as part of such a combination approach to immunotherapy.

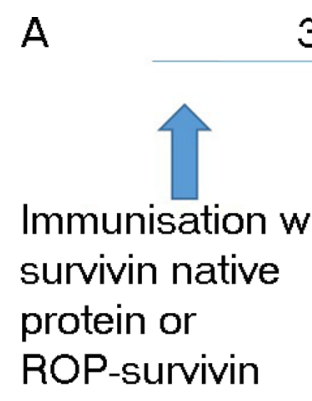

$\mathrm{B}$

\section{Re-stimulate with ROP-survivin}

$$
\begin{aligned}
& \text { Con A stimulation } \\
& \text { (positive control) }
\end{aligned}
$$

\section{3 wks} 3 wks 3 wks

Negative
control

Figure 5: Immunization with ROP-survivin increases survival times in a mouse tumour model. (A) Experimental timeline. Mice were immunized with ROP-survivin $(n=12)$ or native survivin protein $(n=12)$ at day 0 and then further immunized twice at 3 week intervals with antigen ${ }^{+}$MPL. Two mice from each group were sacrificed for ELISpot analysis and the remaining mice were subjected to challenge with B16 cells expressing survivin 3 weeks later. (B) IFN- $\gamma$ release from activated lymphocytes. PBMCs were incubated with an ELISpot test using $50 \mu \mathrm{g} / \mathrm{ml}$ ROP-survivin. (C) Survival rates for mice immunized with ROP-survivin compared to those immunized with native survivin protein following challenge with B16 cells expressing survivin. 


\section{MATERIALS AND METHODS}

\section{Molecular cloning}

We designed synthetic cDNA genes encoding residues 242 to 352 of OVA, native ESAT6 and CFP10 of Mycobacterium tuberculosis, HPV-16 E7, survivin and the respective LRMK linked recombinant overlapping peptides (ROP-OVA, ROP-ESAT6-CFP10, ROP-HPV, ROP-survivin), with codon selection optimized for expression in E. coli. The genes were synthesized by the GeneArt DNA synthesis service. The synthesized cDNAs and the Bsa4 linearized vector pNIC28-Bsa4 (SGC Oxford) were treated with T4 DNA polymerase $\left(30 \mathrm{~min}\right.$ at $22^{\circ} \mathrm{C}$ ) in the presence of $2.5 \mathrm{mM} \mathrm{dCTP}$ and dGTP respectively. T4 DNA polymerase was inactivated by incubation at $80^{\circ} \mathrm{C}$ for $20 \mathrm{~min}$. T4 DNA treated PCR products and vector were mixed at a ratio of 1:50 for 10 $\min$ at $25^{\circ} \mathrm{C}$. An aliquot of ligation products was used to transform DH5a competent cells. The positive clones were identified by colony PCR and the corresponding plasmids were used to transform E.coli BL21 (DE3) for protein expression.

\section{Protein expression and purification}

A single transformed BL21 (DE3) colony was picked into LB ( $50 \mu \mathrm{g} / \mathrm{ml} \mathrm{Kan})$ and cultured overnight at $37^{\circ} \mathrm{C}$. The overnight culture was then diluted 100 times with fresh LB and cultured until the OD600 reached 0.6. Then IPTG was added to final concentration of $0.5 \mathrm{mM}$. The cells were harvested at $16 \mathrm{hr}$ post IPTG induction by centrifugation. The cell pellets were resuspended in lysis buffer $(25 \mathrm{mM}$ Tris- $\mathrm{HCl}, 200 \mathrm{mM} \mathrm{NaCl}, 2 \%$ Triton X-100, $10 \mathrm{mM}$ imidazole, pH8.0) and were lysed by sonication. Insoluble fractions were separated by centrifugation at $20,000 \mathrm{~g}$ for $45 \mathrm{~min}$. For expressed soluble protein, Ni-NTA resin was then added to the soluble fractions for $30 \mathrm{~min}$, followed by washing with 30 resin volumes of lysis buffer and eluted with lysis buffer containing $300 \mathrm{mM}$ imidazole. For proteins forming inclusion bodies, the insoluble fractions were re-suspended in buffer $(25 \mathrm{mM}$ Tris- $\mathrm{HCl}, 200 \mathrm{mM} \mathrm{NaCl}$, $8 \mathrm{M}$ urea, $10 \mathrm{mM}$ imidazole, $\mathrm{pH} 8.0$ ) and centrifuged at $20,000 \mathrm{~g}$ for another $45 \mathrm{~min}$, before applying to the Ni-NTA resin. Washing buffer and elution buffer also contained $8 \mathrm{M}$ urea. For refolding, the eluted proteins were first buffer exchanged to $25 \mathrm{mM}$ Tris- $\mathrm{HCl}, 200$ $\mathrm{mM} \mathrm{NaCl}, 0.5$ arginine- $\mathrm{HCl}, \mathrm{pH} 8.0$ then to PBS using a PD10 column (GE Healthcare Life Sciences, UK).

\section{Maintenance of cell line}

The dendritic cell line DC2.4 was a gift from K. Rock (University of Massachusetts, Worcester, Mass.) and was maintained in RPMI 1640 (Sigma, UK) supplemented with $10 \%$ heat-inactivated fetal calf serum (Sigma), $2 \mathrm{mM}$ l-glutamine.

\section{Patients}

TB and HIV-TB co-infected patients were recruited from the No.2 people's hospital of Dali. Samples and / or data obtained were collected with informed donor consent in full compliance with national and institutional ethical requirements (COREC number COREC06/Q1606/139). All study protocols and consent forms were approved by the institutional review boards of The No.2 People's Hospital of Dali.

\section{Mice and immunization}

C57BL/10 mice were primed subcutaneously with $200 \mu \mathrm{g}$ of ROP-HPV or ROP-survivin emulsified with $50 \mu 1$ of monophosphoryl lipid A (MPL) (Sigma). Mice injected with MPL adjuvant plus HPV-E7 or survivin wild type protein were used as controls. They were boosted subcutaneously twice at 3-week intervals with the same vaccine emulsified with MPL. Three weeks after the last boost, 10 mice of each group were challenged with B16-E7 or B16-survivin, and 2 or 4 mice of each group were used for ELISpot assays.

\section{Isolation of human peripheral blood mononuclear cells (PBMC), B cells, dendritic cells, $T$ cells and murine splenocytes}

Heparin-treated human blood $(10 \mathrm{ml})$ from patients was carefully added to lymphocyte-separation medium $($ density $=1.077)$ and centrifuged at $1500 \mathrm{~g}$ for $25 \mathrm{~min}$. The PBMC layer was transferred to a new tube and washed twice with RPMI 1640 medium. The PBMCs were counted and $10^{5}$ cells/well were used for stimulation.

AntiCD19 Ab (Millipore, Watford, UK) was used to purify $\mathrm{CD} 19^{+} \mathrm{B}$ cells.

DCs were purified from human PBMCs. Briefly, adherent cells from PBMCs were cultured in the presence of $50 \mathrm{IU} / \mathrm{ml} \mathrm{IL-4} \mathrm{(PeproTech,} \mathrm{Rocky} \mathrm{Hill,} \mathrm{US)} \mathrm{and} 1000$ $\mathrm{IU} / \mathrm{ml} \mathrm{GM-CSF}$ (PeproTech, US) for 6 days.

$\mathrm{CD} 19^{+} \mathrm{B}$ cells were purified by attaching PBMCs to anti-CD19 $9^{+}$monoclonal antibody pre-coated plate. Cells were then re-suspended for the next step.

$\mathrm{CD} 8^{+} \mathrm{T}$ cells were purified by negative selection using microbeads kit (Miltenyi, Germany) as per the manufacturer's instructions.

Mouse spleens were meshed and loaded to lymphocyte separation medium Histopaque-1.083 (density $=1.083 \mathrm{~g} \mathrm{ml}-1$; Sigma), and centrifuged at $1500 \mathrm{~g}$ for 25 min before transferring the layered lymphocytes to a new tube with cell culture medium. The cells were washed by RPMI 1640 and $1 \times 10^{5}$ splenocytes/well were used for stimulation in ELISpot assays. 


\section{ELISpot assays}

Assays were performed using ELISpot kits (Mabtech, Sweden). Briefly, PBMCs or splenocytes were re-stimulated overnight with $10 \mu \mathrm{M}$ ROP-ESAT6-CFP10, ROP-HPV, or ROP-survivin in anti-IFN- $\gamma$-Ab precoated plates (Millipore, Bedford, MA). Cells were discarded, and biotinylated anti-IFN $\gamma$ antibodies were added for $2 \mathrm{hr}$ at room temperature, followed by another $1 \mathrm{hr}$ of incubation at room temperature with anti-biotin antibody labeled with enzyme. After colour developed, the reaction was stopped by washing plates with tap water and plates were air-dried. Spots were counted with an Elispot reader (Autoimmun Diagnostike, Strasburg, Germany). Results were expressed as spot forming units $/ 10^{6}$ cells.

\section{Antigen presentation assays}

DC 2.4 cells were plated in 24 well plates $\left(4 \times 10^{5}\right.$ per well) and incubated with the ROP-OVA or OVA proteins (both at $1 \mathrm{mg} / \mathrm{ml}$ in PBS) for $13 \mathrm{hr}$, and followed by flow cytometry analysis.

\section{Flow cytometry}

At $13 \mathrm{hrs}$, cells were harvested by EDTA treatment and washed once using $1 \mathrm{ml}$ ice-cold FACS buffer (2\% FCS in PBS). PE conjugated monoclonal antibody 25.D116 was then added at a final concentration of $0.6 \mu \mathrm{g} / \mathrm{ml}$. Cells were incubated for $30 \mathrm{~min}$ on ice in the dark and washed three times using $1 \mathrm{ml} \mathrm{FACS}$ buffer, re-suspended in $0.2 \mathrm{ml}$ FACS fixing buffer (BD) and analyzed by flow cytometry using FlowJo software (ThreeStar, San Carlos, CA, USA).

\section{Statistical analysis}

Statistical analysis was performed using the Student's $t$ test. $P$ values $\leq 0.05$ were considered significant.

\section{Abbreviations}

APC: Antigen presenting cells; CD19: Surface antigen found on B cells and follicular DCs, involved in up-regulating immune responses; CD4: Surface antigen found on lymphocytes involved in humoral responses; CD8: Surface antigen found on lymphocytes involved in cellular responses; CFP10-ESAT6: A $10 \mathrm{kDa}$ antigen secreted by Mycobacterium tuberculosis; CTLA-4: Cytotoxic T cell antigen 4; DC: Dendritic cell; ER: Endoplasmic reticulum; H-2b: Major histocompatibility complex of the mouse; HPV: Human papilloma virus; MHC: Major histocompatibility complex; PBMC: Peripheral blood mononuclear cells; PD-1: Programmed cell death protein - 1; ROP: Recombinant overlapping peptide; ROP-HPV E7: ROP based on HPV E7 protein; ROP-Ova: ROP based on ovalbumin; ROP-survivin: ROP based on the tumour expressed protein survivin; TB: Tuberculosis; TCR: T cell receptor.

\section{Author contributions}

SJ and WL designed the project and wrote the manuscript; LC performed most of the experiments; JZ was key to clinical experimental design and organization; RZ helped to perform most of the protein expression and purification experiments; JG and KW helped to organize patients' samples; WS carried out some of the antigen presentation assays; XX made constructs and performed some flow cytometry experiments. AC, WF were involved in organization of the projects; $\mathrm{ME}$ and $\mathrm{SO}$ were involved in compiling the final draft of the manuscript.

\section{FUNDING}

This study was supported by grants from Oxford Vacmedix Ltd, The Mary Kinross Charitable Trust (SO and SJ) and the Workstation of Academician Zeng Yi, project No.: 2014IC027 (JZ, JG an KC).

\section{CONFLICTS OF INTEREST}

Oxford Vacmedix Ltd is a spinoff company from University of Oxford. It is dedicated to develop ROP technology for vaccines and diagnostics. The company owns patents relating to the project.

\section{REFERENCES}

1. Mempel TR, Henrickson SE, Von Andrian UH. T-cell priming by dendritic cells in lymph nodes occurs in three distinct phases. Nature. 2004; 427:154-159.

2. Blair DA, Dustin ML. T cell priming goes through a new phase. Nature immunology. 2013; 14:311-312.

3. Heemels MT, Ploegh H. Generation, translocation, and presentation of MHC class I-restricted peptides. Annual review of biochemistry. 1995; 64:463-491.

4. Turley SJ, Inaba K, Garrett WS, Ebersold M, Unternaehrer J, Steinman RM, Mellman I. Transport of peptide-MHC class II complexes in developing dendritic cells. Science. 2000; 288:522-527.

5. Heath WR, Carbone FR. Cross-presentation, dendritic cells, tolerance and immunity. Annual review of immunology. 2001; 19:47-64.

6. Ackerman AL, Cresswell P. Cellular mechanisms governing cross-presentation of exogenous antigens. Nature immunology. 2004; 5:678-684.

7. Burgdorf S, Kautz A, Bohnert V, Knolle PA, Kurts C. Distinct pathways of antigen uptake and intracellular 
routing in CD4 and CD8 T cell activation. Science. 2007; 316:612-616.

8. Burgdorf S, Scholz C, Kautz A, Tampe R, Kurts C. Spatial and mechanistic separation of cross-presentation and endogenous antigen presentation. Nature immunology. 2008; 9:558-566.

9. Ura T, Okuda K, Shimada M. Developments in Viral VectorBased Vaccines. Vaccines (Basel). 2014; 2:624-641.

10. Jiang S, Song R, Popov S, Mirshahidi S, Ruprecht RM. Overlapping synthetic peptides as vaccines. Vaccine. 2006; 24:6356-6365.

11. Sabbatini P, Tsuji T, Ferran L, Ritter E, Sedrak C, Tuballes K, Jungbluth AA, Ritter G, Aghajanian C, Bell-McGuinn K, Hensley ML, Konner J, Tew W, et al. Phase I trial of overlapping long peptides from a tumor self-antigen and poly-ICLC shows rapid induction of integrated immune response in ovarian cancer patients. Clinical cancer research. 2012; 18:6497-6508.

12. van Poelgeest MI, Welters MJ, van Esch EM, Stynenbosch LF, Kerpershoek G, van Persijn van Meerten EL, van den Hende M, Lowik MJ, Berends-van der Meer DM, Fathers LM, Valentijn AR, Oostendorp J, Fleuren GJ, et al. HPV16 synthetic long peptide (HPV16-SLP) vaccination therapy of patients with advanced or recurrent HPV16-induced gynecological carcinoma, a phase II trial. Journal of translational medicine. 2013; 11:88.

13. Rosalia RA, Quakkelaar ED, Redeker A, Khan S, Camps M, Drijfhout JW, Silva AL, Jiskoot W, van Hall T, van Veelen PA, Janssen G, Franken K, Cruz LJ, et al. Dendritic cells process synthetic long peptides better than whole protein, improving antigen presentation and T-cell activation. Eur J Immunol. 2013; 43:2554-2565.
14. Zhang H, Hong H, Li D, Ma S, Di Y, Stoten A, Haig N, Di Gleria K, Yu Z, Xu XN, McMichael A, Jiang S. Comparing pooled peptides with intact protein for accessing crosspresentation pathways for protective $\mathrm{CD} 8^{+}$and $\mathrm{CD} 4^{+} \mathrm{T}$ cells. The Journal of biological chemistry. 2009; 284:9184-9191.

15. Lutzner N, Kalbacher H. Quantifying cathepsin S activity in antigen presenting cells using a novel specific substrate. The Journal of biological chemistry. 2008; 283:36185-36194.

16. Ruckrich $\mathrm{T}$, Brandenburg J, Cansier A, Muller M, Stevanovic S, Schilling K, Wiederanders B, Beck A, Melms A, Reich M, Driessen C, Kalbacher H. Specificity of human cathepsin $\mathrm{S}$ determined by processing of peptide substrates and MHC class II-associated invariant chain. Biological chemistry. 2006; 387:1503-1511.

17. Clement H, Flores V, Diego-Garcia E, Corrales-Garcia L, Villegas E, Corzo G. A comparison between the recombinant expression and chemical synthesis of a short cysteine-rich insecticidal spider peptide. J Venom Anim Toxins Incl Trop Dis. 2015; 21:19.

18. Moynihan KD, Opel CF, Szeto GL, Tzeng A, Zhu EF, Engreitz JM, Williams RT, Rakhra K, Zhang MH, Rothschilds AM, Kumari S, Kelly RL, Kwan BH, et al. Eradication of large established tumors in mice by combination immunotherapy that engages innate and adaptive immune responses. Nat Med. 2016; 22:1402-1410.

19. Swart M, Verbrugge I, Beltman JB. Combination Approaches with Immune-Checkpoint Blockade in Cancer Therapy. Front Oncol. 2016; 6:233. 